\title{
Stuck in the Unit: Three-Year Outcomes Following Prolonged Stay in the Surgical Intensive Care Unit
}

\author{
Eileen Eggenberger ${ }^{1}$, Samuel Marquez ${ }^{2}$, Thu Doan', David M. Radosevich', \\ Jeffrey G. Chipman', Kaysie L. Banton'1, Greg J. Beilman1 \\ ${ }^{1}$ Department of Critical Care and Acute Care Surgery, University of Minnesota, Minneapolis, MN, USA \\ ${ }^{2}$ Department of Surgery, Mercy Hospital, St. Louis, MO, USA \\ Email: beilm001@umn.edu
}

Received 22 June 2014; revised 20 July 2014; accepted 19 August 2014

Copyright (C) 2014 by authors and Scientific Research Publishing Inc.

This work is licensed under the Creative Commons Attribution International License (CC BY). http://creativecommons.org/licenses/by/4.0/

Open Access

\begin{abstract}
Introduction: Advances in care of the critically ill patient have promoted growth in the number of "chronically critically ill"-patients who survive acute medical crisis only to require weeks of intensive monitoring. This population accounts for a small fraction of admissions yet a disproportionately large fraction of healthcare resources. Despite this allocation, long-term outcomes are poorly understood. The goal of this study is to determine the rate of mortality in the 3 years following prolonged admission to the surgical intensive care unit. Methods: This retrospective study includes patients discharged from a twenty-bed surgical intensive care unit in an 874-bed tertiary care academic hospital. All patients who were at least 18 years old, spent at least 30 consecutive days in the surgical intensive care unit, and were discharged during 2002-2009 were eligible for inclusion in the study. Patients were followed for 3 years following discharge. Age, sex, length of hospital stay, length of surgical intensive care unit stay, and admitting diagnosis were abstracted from medical records. For living patients, ventilator-dependence at discharge and disposition to rehabilitation facility were documented. Date of death was determined from medical records and the Social Security Death Master File. Using a proportional hazards model, these patient variables were analyzed for their contribution to mortality during admission as well as at 1 year and 3 years post discharge. Results: Sixty-four patients were included in the study: 35 males and 29 females with a mean age of $59(21-83)$ years, surgical intensive care unit stay of 47 (30 - 125) days, and hospital stay of 58 (30 - 178) days. Thirty patients died during admission, 16 died within 1 year of discharge, and an additional 4 patients died within 3 years. Among those discharged, $70 \%$ of deaths occurred within 3 months. No variables were identified as independent risk factors for mortality. Conclusions: An increasing number of patients are admitted for prolonged stays in the surgical intensive care unit. The human cost of prolonged surgical intensive care unit admission is high with $\mathbf{7 0} \%$ of patients succumbing during admission or within the first year after discharge.
\end{abstract}




\section{Keywords}

\section{Surgery, Critical Care, Long-Term Outcomes}

\section{Introduction}

Advances in critical care medicine have resulted in the increasing occurrence of the "chronically critically ill" (CCI)-patients who survive an acute crisis, previously considered fatal, only to require weeks of life-sustaining therapies in intensive care units (ICU). There is no common etiology or clinical course to define CCI, but most CCI patients have multiple comorbid conditions [1] and definition focuses on either length of mechanical ventilation or length of ICU admission [2]. Despite the challenge in classifying patients, it is clear that the CCI population is growing and forcing a change in the landscape of critical care medicine. Currently CCI patients account for $6 \%-10 \%$ of ICU admissions but utilize $30 \%-50 \%$ of resources [1] [2]. This disproportionate allocation stresses hospital resources even though there is no clear understanding of the long-term morbidity and mortality associated with this situation [1] [3].

In the United States, care of patients within intensive care units consumes more than $13 \%$ of hospital resources and is estimated to have an annual cost of $\$ 81.7$ billion. The greatest contributors to costs are the number of ICU beds and the number of days used. The United States has the highest ICU bed-to-population and ICU-to-hospital bed ratios [4]. During the past 20 years, increased reliance on outpatient care has made it possible for US hospitals to decrease their total number of beds, but their number of critical care beds have steadily increased [2] [4]. The net result is an increased proportion of ICU beds within the inpatient setting. Still, the anticipated increase in the number of CCI patients outpaces the ability of the current ICU system to adapt [5] [6]; by 2020 it is expected that the CCI population will have doubled in size from 2000 [7].

Unanticipated long-term use of critical care beds for CCI patients reduces the number of ICU beds available for more acutely ill patients. Even a short delay ( $\geq 6$ hours) in transferring acutely ill patients from the emergency department to ICU increases mortality. Transfer delays also result in increased length of stay, use of ventilators, and placement of central venous catheters [8]. This cycle exacerbates the demands placed on the ICU.

The growing CCI patient population is taxing the healthcare system in the United States, but few studies have evaluated patient outcomes achieved by prolonged management in the SICU. This study seeks to measure longterm outcomes, specifically mortality, for CCI patients admitted to the surgical ICU (SICU). We also hope to identify risk factors for mortality that can be used to guide patients, families, and physicians in discussions concerning end-of-life care.

\section{Materials and Methods}

This was a retrospective study conducted at the University of Minnesota Medical Center Fairview, an 874-bed tertiary care center with a 20-bed SICU that admits 1200 patients/year. The SICU is a closed unit. Cardiothoracic and neurosurgical intensive care patients are managed in other intensive care units. All patients $\geq 18$ years old who spent $\geq 30$ consecutive days in the SICU and were discharged from the hospital between January 1, 2002 and December 31, 2009 were eligible for inclusion in the study.

A two-step process was used to identify patients because the electronic medical records (EMR) system was not designed to track time admitted to specific units. First, patients were identified using PASS, internally developed software used as a master patient index, registration system, and billing system. PASS selected patients based on three criteria: $\geq 18$ years old, hospital stay $\geq 30$ days, and discharge from the SICU between January 1 , 2002 and December 31, 2009. Then each patient's medical record was manually reviewed to determine the number of days spent in the SICU and only those with $\geq 30$ consecutive days were enrolled in the study. Only the longest stay was considered for patients with multiple SICU admissions during the same hospitalization. Our institutional IRB waived requirement for informed consent.

Age, sex, length of hospital stay, and length of SICU stay were obtained from the medical records. Medical records were also used to classify patient's admission diagnosis into one of eight broad categories: cardiac, vascular, pulmonary, renal/GI/abdominal, abdominal transplant, cancer, infection, or infection transplant. For patients discharged from the hospital, ventilator-dependence at the time of discharge and disposition to rehabilita- 
tion facility were documented based on documentation in the medical record. Date of death was determined from medical records if death occurred in the hospital or from the Social Security Death Master File (SSDMF) if patients were discharged. Access to the SSDMF was obtained via subscription to Genealogy Bank [9]. Patients were presumed living if there was no record in the SSDMF. Patients were followed for three years from the date of their discharge from the SICU.

A proportional hazards model was used to identify independent risk factors for mortality, both in the SICU and in the 3 years following discharge. Age, sex, length of hospital stay, length of SICU stay, and admission diagnosis were evaluated for their influences on survival in the SICU and following discharge. In addition, ventilator-dependence and disposition to a rehabilitation facility were considered for survival following discharge. Variables were considered statistically significant if $\mathrm{p}<0.05$.

\section{Results}

Of patients admitted to the SICU during the inclusion time period, 137 patients were identified with the PASS software query of the EMR. Manual review of the medical records narrowed the study group to 64 patients with SICU stay $\geq 30$ days. All 64 patients, 35 males and 29 females, were included in the study. The mean age was 59 (21 - 83) years old. The mean length of stay in the SICU was $47(30$ - 125) days and the total hospital stay was 58 (30 - 178) days. Ten patients were admitted with cardiac diagnoses, 8 with vascular, 5 with pulmonary, 10 with renal/GI/abdominal, 5 with abdominal transplant, 12 with cancer, 6 with infection, 5 with solid organ transplant and infection, and 2 patients with diagnosis outside these categories (Table 1).

Mortality was high: 30 (47\%) patients died during admission, 16 (25\%) died within 1 year of SICU discharge, and $4(6 \%)$ more died within 3 years. Of the 34 patients discharged from the hospital, 11 were ventilator- dependent and 20 were discharged to rehabilitation facilities. After leaving the hospital, risk of death was greatest in the first months following discharge; $70 \%$ of deaths occurred during the first 3 months following discharge and mean survival following discharge was only 411 days (Figure 1).

Despite high mortality, we were unable to identify variables that definitively contributed to worse outcomes. The proportional hazards model did not isolate age, sex, length of SICU stay, length of hospital stay, or admission diagnosis as statistically significant risk factors for death during SICU admission. Initial analysis included all the variables but this subdivided the data too greatly for meaningful interpretation of the results. Therefore,

\begin{tabular}{lc}
\multicolumn{2}{c}{ Table 1. Summary of patient demographics } \\
\hline \multicolumn{2}{c}{ Patient Demographics, N $=64$} \\
\hline Mean Age & Years (Range) \\
Mean Length of Stay $(21-83)$ \\
SICU & Days (Range) \\
Hospital & $47(30-125)$ \\
Sex & $58(30-178)$ \\
Male & Number of Patients \\
Female & 35 \\
Admission Diagnosis & 29 \\
Cardiac & Number of Patients \\
Vascular & 10 \\
Pulmonary & 8 \\
Renal/GI/Abdominal & 5 \\
Abdominal Transplant & 10 \\
Cancer & 5 \\
Infection & 12 \\
Infection Transplant & 6 \\
Other & 5 \\
\hline
\end{tabular}




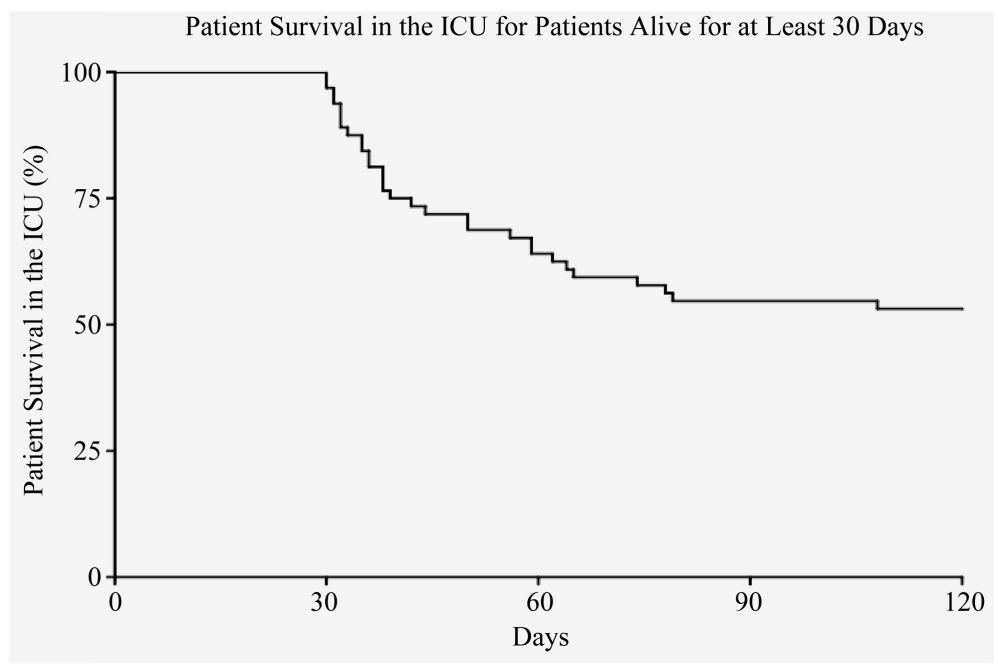

(a)

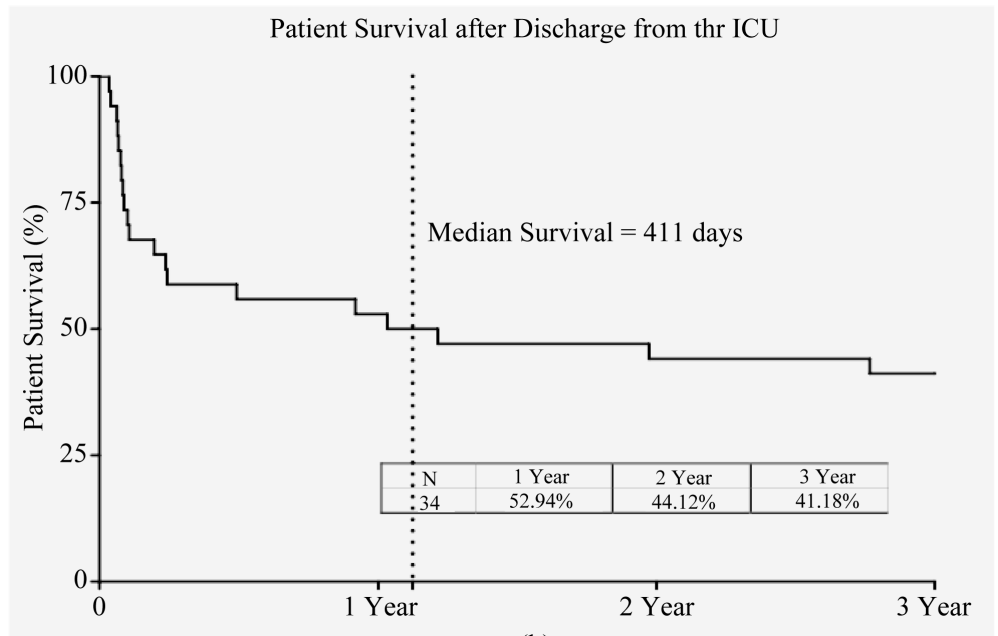

(b)

Figure 1. Kaplan-Meier survival curves (a) during SICU admission, N = 64 and (b) following discharge. The first three months following discharge were most critical; $70 \%$ of post-discharge deaths occurred during this period.

analysis was repeated with only the variables that demonstrated the greatest potential for statistical significance after the initial analysis: age, female sex, and length of SICU admission. Despite the more simplified analysis, none of the three variables had a statistically significant impact on mortality (Table 2). Similar analysis was completed for mortality following discharge as 1 and 3 year. Age, female sex, cardiac-related admission diagnosis, cancer-related admission diagnosis, and disposition status were identified as the most likely contributors to mortality, but, again, further analysis showed no statistical significance (Figure 2 and Figure 3).

\section{Discussion}

An increased number of chronically critically ill patients are admitted to the SICU each year in the United States. Analysis has shown that cost of care for CCI patients is much higher than that of the average critical care patient [1] [2]. One of the greatest contributors to the cost of care is the number of bed days [4]. The patients included in this study account for $<1 \%$ of the annual admissions to our SICU, but utilize $6 \%$ of bed days. Mortality is the most primitive measure of patient outcome but often the primary driving factor when physicians, patients, and patient families make decisions about care. Extended stays in the SICU are difficult for patients and their families, and their decisions may change as the prognosis worsens. Mortality in our SICU is $2 \%$ but soars to $47 \%$ for the CCI. 
Table 2. Hazard Ratios calculated for risk of mortality during SICU admission. Though age, sex, and lengh of admission to the SICU were identified as the variables with the greatest potential to achieve statistical significance $(\mathrm{p}<0.05)$, none achieved statistical significance in the Proportional Hazard Model.

\begin{tabular}{ccc}
\hline & Hazard Ratio & $\mathrm{p}$ \\
\hline Age & 1.007 & 0.5948 \\
Female & 1.042 & 0.9122 \\
Length of ICU Stay & 1.007 & 0.2562 \\
\hline
\end{tabular}

Patient Mortality in the 1st year following discharge: Hazard ratio for variables of interest

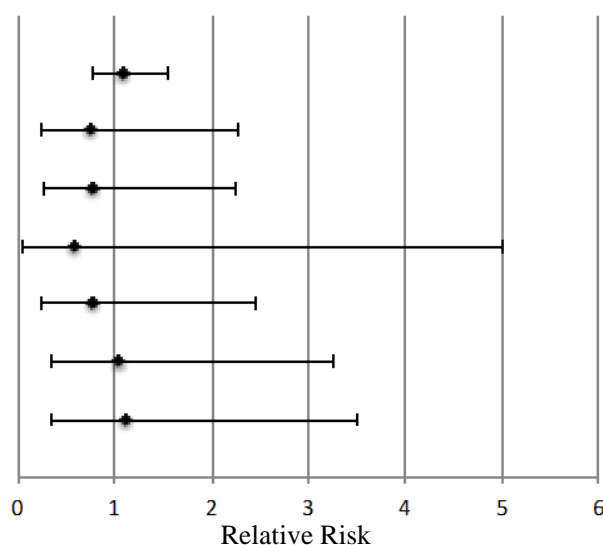

- Age

४ Sex: Female

- Length of ICU stay

- Admission Diagnosis: Heart

- Admission Diagnosis: Cancer

- Disposition: Rehabilitation Facility

- Disposition: Ventilator Dependent

Figure 2. Risk of 1-year Mortality (34 patients included, 16 died). Error bars represent confidence intervals. Age was analyzed using 10-year intervals and SICU length of stay was analyzed using 30-day intervals. Therefore, point estimates are reported in place of hazard ratios for these two variables. None of the variables proved to have a statistically significant effect on mortality at 1 year after discharge from the SICU.

Patient Mortality 3 year following discharge: Hazard ratios for variables of interest

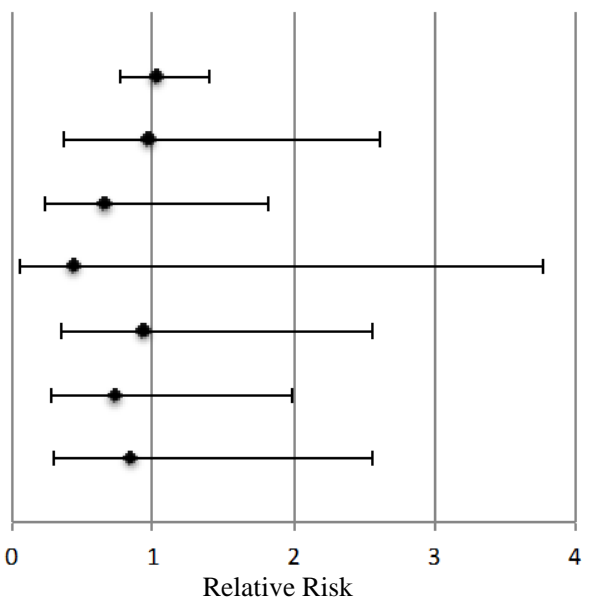

- Age

- Sex: Female

- Length of ICU stay

- Admission Diagnosis: Heart

- Admission Diagnosis: Cancer

- Disposition: Rehabilitation Facility

- Disposition: Ventilator Dependent

Figure 3. Risk of 3-year mortality (34 patients included, 20 died). Error bars represent confidence intervals. Age was analyzed using 10-year intervals and SICU length of stay was analyzed using 30-day intervals. Therefore, point estimates are reported in place of hazard ratios for these two variables. None of the variables proved to have a statistically significant effect on mortality at 3 years following discharge from the SICU. 
Prolonged stays in the ICU have been defined from as short as $48 \mathrm{hr}$ to more than 30 days [10]. Mortality rates directly correlate with length of stay until day 16 when both hospital mortality and 1-year post-discharge mortality plateaus [11]. Though other studies have been conducted with similar intent to determine the prognosis of prolonged stays in the ICU (Table 3), only Hartl, et al., and Weiler, et al., have studied outcomes for surgical ICU patients with stays $\geq 16$ days, narrowing their focus to the patient group with the greatest mortality. Both studies were conducted in Germany and report mortality rates comparable to our results [3] [10]. Hartl, et al., in a much larger study with 390 patients, found $46 \%$ mortality in the SICU and $67 \%$ mortality in the first year following discharge [3], nearly identical to the $47 \%$ and $72 \%$ mortality found in our study. Hartl, et al., didn't report 3 year-outcomes, but found $76 \%$ mortality at 2 years post-discharge and $80 \%$ at 5 years, sandwiching the 3-year mortality found in our study. Weiler, et al., reported 43\% SICU mortality and 61\% 1-year mortality for the 67 patients studied [10]. In addition to reporting mortality, Hartl, et al., found increased mortality with advanced patient age [3]. It is possible that our study was underpowered to identify age as a statistically significant prognostic factor.

Comparison between studies is difficult. Over time the average age in the critical care unit has increased and

Table 3. Summary of studies reporting patient outcomes following prolonged admission to intensive care units. Depending on the study, length of survival was measured from the date of admission, the date of ICU discharge, or the date of hospital discharge.

\begin{tabular}{|c|c|c|c|c|c|c|c|c|}
\hline First Author & Year & Population (Number of Enrollees) & $\begin{array}{l}\text { Length of } \\
\text { ICU Stay }\end{array}$ & $\begin{array}{c}\text { Mean } \\
\text { LOS }^{\mathbf{a}} \\
\text { (Range) }\end{array}$ & $\begin{array}{c}\text { ICU } \\
\text { Mortality }\end{array}$ & $\begin{array}{l}\text { Hospital } \\
\text { Mortality }\end{array}$ & $\begin{array}{l}\text { Long-Term } \\
\text { Mortality }\end{array}$ & Location \\
\hline Venker [13] & 2005 & General ICU (78) & $>60$ days & 86 & $38 \%$ & $49 \%$ & $\begin{array}{l}1 \text { year: } 56 \% \\
5 \text { years: } 67 \%\end{array}$ & Netherlands \\
\hline Present Study & 2014 & Surgical ICU (64) & $\geq 30$ days & $\begin{array}{c}47(30- \\
125)\end{array}$ & $47 \%$ & & $\begin{array}{l}1 \text { year: } 72 \% \\
3 \text { years: } 78 \%\end{array}$ & United States \\
\hline Karth [14] & 2006 & Mixed cardiologic ICU (135) & $\geq 30$ days & 39 & $21 \%$ & $34 \%$ & $\begin{array}{l}1 \text { year: } 55 \% \\
2 \text { years: } 63 \% \\
4 \text { years: } 74 \%\end{array}$ & Austria \\
\hline Friedrich [15] & 2005 & Medical/surgical ICU (182) & $\geq 30$ days & 49 & $32 \%$ & $42 \%$ & 6 months: $50 \%$ & Canada \\
\hline Hughes [16] & 2001 & General ICU (323) & $\geq 30$ days & 43 & $27 \%$ & $40 \%$ & & Scotland \\
\hline $\begin{array}{l}\text { Montuclard } \\
{[17]}\end{array}$ & 2000 & General ICU, >70 years old (75) & $\geq 30$ days & $\begin{array}{c}53(31- \\
139)\end{array}$ & $33 \%$ & $53 \%$ & $\begin{array}{l}1 \text { year: } 59 \% \\
2 \text { years: } 63 \%\end{array}$ & France \\
\hline Gracey [18] & 1992 & Mechanical ventilation & $>29$ days & & & $40 \%$ & $\begin{array}{l}1 \text { year: } 61 \% \\
2 \text { years: } 65 \% \\
3 \text { years: } 67 \%\end{array}$ & United States \\
\hline Hartl [3] & 2007 & Surgical ICU (390) & $\geq 28$ days & 63 & $46 \%$ & & $\begin{array}{l}1 \text { year: } 67 \% \\
2 \text { years: } 76 \% \\
5 \text { years: } 80 \%\end{array}$ & Germany \\
\hline Soares [19] & 2008 & $\begin{array}{c}\text { General ICU, cancer or remission } \\
<5 \text { years }(163)\end{array}$ & $\geq 21$ days & & $26 \%$ & $82 \%$ & $\begin{array}{l}6 \text { months: } \\
98 \%\end{array}$ & Brazil \\
\hline Martin [20] & 2005 & $\begin{array}{l}\text { Teaching hospital (TH) ICU (115) } \\
\text { Community hospital (CH) ICU (126) }\end{array}$ & $\begin{array}{l}\mathrm{TH}: \geq 21 \text { days } \\
\mathrm{CH}: \geq 10 \text { days }\end{array}$ & $\begin{array}{l}\text { TH: } 46 \\
\text { CH: } 21\end{array}$ & $\begin{array}{l}\text { TH: } 27 \% \\
\text { CH: } 20 \%\end{array}$ & $\begin{array}{l}\text { TH: } 37 \% \\
\text { CH: } 31 \%\end{array}$ & & Canada \\
\hline Weiler [10] & 2012 & Surgical ICU (67) & $\geq 20$ days & & $43 \%$ & & 1 year: $61.2 \%$ & Germany \\
\hline Fakhry [21] & 1996 & Surgical ICU (83) & $>14$ days & $\begin{array}{c}26 \\
(14-81)\end{array}$ & $25 \%$ & $37 \%$ & & United States \\
\hline Laupland [22] & 2005 & General ICU (216) & $\geq 14$ days & & $25 \%$ & $40 \%$ & 1 year: $44 \%$ & Canada \\
\hline Rimachi [23] & 2007 & Medical/surgical ICU (189) & $>10$ days & $\begin{array}{c}17 \\
(11-70)\end{array}$ & $35 \%$ & $44 \%$ & 1 year: $63 \%$ & Belgium \\
\hline Gaundino [24] & 2007 & ICU, post cardiac surgery (121) & $\geq 10$ days & & & $53 \%$ & 6 years: $\sim 80 \%$ & Italy \\
\hline Lipsett [25] & 2000 & Surgical ICU (128) & $\geq 7$ days & $\begin{array}{c}11 \\
(7-77)\end{array}$ & $40 \%$ & $41 \%$ & 1 year: $54 \%$ & United States \\
\hline Madoff [26] & 1985 & Surgical ICU (63) & $\geq 7$ days & $\begin{array}{c}21 \\
(7-152)\end{array}$ & $41 \%$ & & & United States \\
\hline
\end{tabular}

a. LOS (Length of Stay). 
medical care has improved so that patients with greater comorbidities are considered for procedures from which they'd previously be excluded [10]. The patient mix in ICUs is also variable. Our hospital has separate ICUs for medical, cardiovascular, and neurosurgical patients. We also do not care for trauma patients. Furthermore, there is no universal definition of "chronically critically ill". Common criteria include time of ventilator use, tracheostomy identified by diagnosis-related groups, length of stay, or a variation of these themes. Identification of CCI patients by length of stay is most inclusive because it captures the CCI patients who do not require respiratory aid [12].

Even though length of stay is the most inclusive criterion, it is probable that we were unable to capture every patient that met our study's inclusion criteria. In our EMR system, records can't be queried for length of admission to a specific unit. While we believe we captured the majority of applicable patients, we did not capture patients who were discharged from a step-down unit following prolonged SICU admission during the same hospital admission. Six of the patients included in this study had a similar scenario and were captured by chance; after their prolonged SICU stay, they were transferred to the floor, transferred back to the SICU for a brief stay $(<30$ days), and ultimately discharged from the SICU. Had they not returned to the SICU, we would not have identified them for inclusion in the study even though they met criteria.

Quality of life following a prolonged stay in the ICU is another important outcome measure that contributes to an understanding of CCI patients. Despite the retrospective nature of this study, our original intent was to assess quality of life using the Short Form (SF)-36v2 questionnaire. Our IRB permitted mailing of the survey to the addresses in the medical record but did not permit phone contact. The response rate was too low to generate meaningful information. Patients may consider quality of life as equally important as survival so it is an important consideration when counseling patients facing prolonged SICU admission.

The primary limitation of this study is the relatively small number of patients who met inclusion criteria over the seven year collection period. We believe most patients who met criteria were captured through EMR query, but it is probable that some were not identified. The study is also limited in that long-term outcomes are based solely on mortality rather than morbidity, though both are important components of patient outcome and contribute to the understanding of chronically critically ill patients.

\section{Conclusion}

An accurate prediction of quality of life and mortality following prolonged SICU hospitalization will allow the healthcare system to plan for the growing CCI population. Hospitals will be able to allocate the appropriate number of beds and other resources so that care is optimized for CCI patients without compromising care of the other patients in the SICU. Prognostic information will also help patients and their families make end-of-life decisions. Establishing the current in-hospital mortality and post-discharge mortality is just the first step for determining how the health care system can accommodate needs of chronically critically ill patients.

\section{References}

[1] Wienek, C. and Winkelman C. (2010) Chronic Critical Illness: Prevalence, Profile, and Pathophysiology. AACN Advanced Critical Care, 21, 44-61. http://dx.doi.org/10.1097/NCI.0b013e3181c6a162

[2] Carson, S. (2012) Definitions and Epidemiology of the Chronically Critically Ill. Respiratory Care, 57, 848-858. http://dx.doi.org/10.4187/respcare.01736

[3] Hartl, W.H., Wolf, H., Schneider, C.P., Küchenhoff, H. and Jauch, K.-W. (2007) Acute and Long-Term Survival in Chronically Critically Ill Surgical Patients: A Retrospective Observational Study. Critical Care, 11, R55. http://dx.doi.org/10.1186/cc5915

[4] Pastores, S.M., Dakwar, J. and Halpern, N.A. (2012) Costs of Critical Care Medicine. Critical Care Clinics, 28, 1-10. http://dx.doi.org/10.1016/j.ccc.2011.10.003

[5] Rudy, E.B., Daly B.J., Douglas, S., Montenegro, H.D., Song, R. and Dyer, M.A. (1995) Patient Outcomes for the Chronically Critically Ill: Special Care Unit versus Intensive Care Unit. Nursing Research, 44, 324-331. http://dx.doi.org/10.1097/00006199-199511000-00002

[6] Daly, B.J., Douglas, S.L., Kelley, C.G., O’Toole, E. and Montenegro, H. (2005) Trial of a Disease Management Program to Reduce Hospital Readmissions of the Chronically Critically Ill. Chest, 128, 507-517. http://dx.doi.org/10.1378/chest.128.2.507

[7] Zilberberg, M.D. and Shorr, A.F. (2008) Prolonged Acute Mechanical Ventilation and Hospital Bed Utilization in 2020 
in the United States: Implications for Budgets, Plant, and Personnel Planning. BMC Health Services Research, 8, 242242. http://dx.doi.org/10.1186/1472-6963-8-242

[8] Chalfin, D.B., Trzeciak, S., Likourezos, A., Baumann, B.M. and Dellinger, R.P. (2007) Impact of Delayed Transfer of Critically Ill Patients from the Emergency Department of the Intensive Care Unit. Critical Care Medicine, 35, 14771483. http://dx.doi.org/10.1097/01.CCM.0000266585.74905.5A

[9] Genealogy Bank. www.genealogybank.com

[10] Weiler, N., Waldmann, J., Bartsch, D.K., Rolfes, C. and Fendrich, V. (2012) Outcome in Patients with Long-Term Treatment in a Surgical Intensive Care Unit. Langenbeck’s Archives of Surgery, 397, 995-999. http://dx.doi.org/10.1007/s00423-012-0966-0

[11] Huang, Y.C., Huang, S.J., Tsauo, J.Y. and Ko, W.J. (2010) Definition, Risk Factors and Outcomes of Prolonged Surgical Intensive Care Unit Stay. Anaesthesia and Intensive Care, 38, 500-505.

[12] Carson, S.S. and Bach, P.B. (2002) The Epidemiology and Costs of Chronic Critical Illness. Critical Care Clinics, 18, 461-476. http://dx.doi.org/10.1016/S0749-0704(02)00015-5

[13] Venker, J., Miedema, M., Strack van Schijndel, R.J.M., Girbes, A.R.J. and Groeneveld, A.B.J. (2005) Long-Term Outcome after 60 Days of Intensive Care. Anaesthesia, 60, 541-546. http://dx.doi.org/10.1111/j.1365-2044.2005.04180.x

[14] Karth, G.D., Meyer, B., Bauer, S., Nikfardjam, M. and Heinz, G. (2006) Outcome and Functional Capacity after Prolonged Intensive Care Unit Stay. Wiener Klinische Wochenschrift, 118, 390-396. http://dx.doi.org/10.1007/s00508-006-0616-z

[15] Friedrich, J.O., Wilson, G. and Chant, C. (2006) Long-Term Outcomes and Clinical Predictors of Hospital Mortality in Very Long Stay Intensive Care Unit Patients: A Cohort Study. Critical Care, 10, R59. http://dx.doi.org/10.1186/cc4888

[16] Hughes, M., MacKirdy, F.N., Norrie, J. and Grant, I.S. (2001) Outcome of Long-Stay Intensive Care Patients. Intensive Care Medicine, 27, 779-782. http://dx.doi.org/10.1007/s001340100896

[17] Montuclard, L., Garrouste-Orgeas, M., Timsit, J.F., Misset, B., De Jonghe, B. and Carlet, J. (2000) Outcome, Functional Autonomy, and Quality of Life of Elderly Patients with a Long-Term Intensive Care Unit Stay. Critical Care Medicine, 28, 3389-3395. http://dx.doi.org/10.1097/00003246-200010000-00002

[18] Gracey, D.R., Naessens, J.M., Krishan, I. and Marsh, H.M. (1992) Hospital and Posthospital Survival in Patients Mechanically Ventilated for More than 29 Days. Chest, 101, 211-214. http://dx.doi.org/10.1378/chest.101.1.211

[19] Soares, M., Salluh, J.I.F., Torres, V.B.L., Leal, J.V.R. and Spector, N. (2008) Short- and Long-Term Outcomes of Critically Ill Patients with Cancer and Prolonged ICU Length of Stay. Chest, 134, 520-526. http://dx.doi.org/10.1378/chest.08-0359

[20] Martin, C.M., Hill, A.D., Burns, K. and Chen, L.M. (2005) Characteristics and Outcomes for Critically Ill Patients with Prolonged Intensive Care Unit Stays. Critical Care Medicine, 33, 1922-1927. http://dx.doi.org/10.1097/01.CCM.0000178184.97813.52

[21] Fakhry, S.M., Kercher, K.W. and Rutledge, R. (1996) Survival, Quality of Live, and Charges in Critically Ill Surgical Patients Requiring Prolonged ICU Stays. Journal of Trauma-Injury Infection \& Critical Care, 41, 999-1007. http://dx.doi.org/10.1097/00005373-199612000-00010

[22] Laupland, K.B., Kirkpatrick, A.W., Kortbeek, J.B. and Zuege, D.J. (2006) Long-Term Mortality Outcome Associated with Prolonged Admission to the ICU. Chest, 129, 954-959. http://dx.doi.org/10.1378/chest.129.4.954

[23] Rimachi, R., Vincent, J.L. and Brimioulle, S. (2007) Survival and Quality of Life after Prolonged Intensive Care Unit Stay. Anaesthesia and Intensive Care, 35, 62-67.

[24] Gaudino, M., Girola, F., Piscitelli, M., Martinelli, L., Anselmi, A., Della Vella, C., Schiavello, R. and Possati, G. (2007) Long-Term Survival and Quality of Life of Patients with Prolonged Postoperative Intensive Care Unit Stay: Unmasking an Apparent Success. Journal of Thoracic and Cardiovascular Surgery, 134, 465-469. http://dx.doi.org/10.1016/j.jtcvs.2007.04.028

[25] Lipsett, P.A., Swoboda, S.M., Dickerson, J., Ylitalo, M., Gordon, T., Breslow, M., Campbell, K., Dorman, T., Pronovost, P. and Rosenfeld, B. (2000) Survival and Functional Outcome after Prolonged Intensive Care Unit Stay. Annals of Surgery, 231, 262-268. http://dx.doi.org/10.1097/00000658-200002000-00016

[26] Madoff, R.D., Sharpe, S.M., Fath, J.J., Simmons, R.L. and Cerra, F.B. (1985) Prolonged Surgical Intensive Care. JAMA Surgery, 120, 698-702. http://dx.doi.org/10.1001/archsurg.1985.01390300048008 
Scientific Research Publishing (SCIRP) is one of the largest Open Access journal publishers. It is currently publishing more than 200 open access, online, peer-reviewed journals covering a wide range of academic disciplines. SCIRP serves the worldwide academic communities and contributes to the progress and application of science with its publication.

Other selected journals from SCIRP are listed as below. Submit your manuscript to us via either submit@scirp.org or Online Submission Portal.
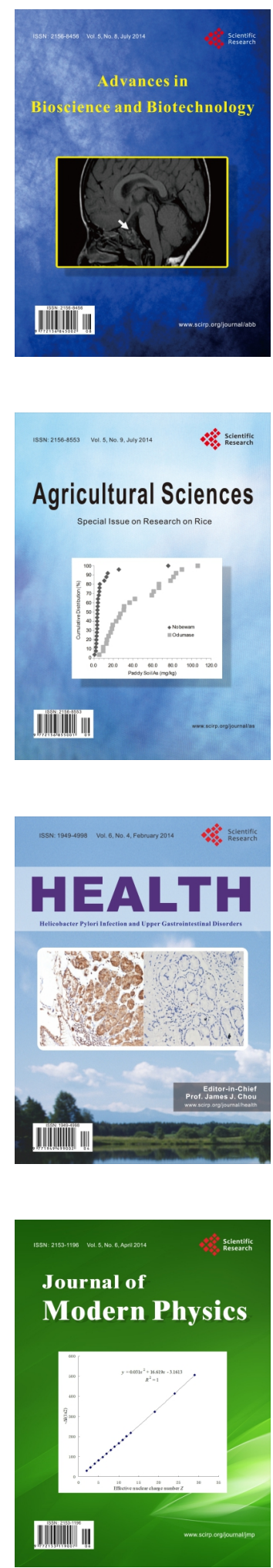
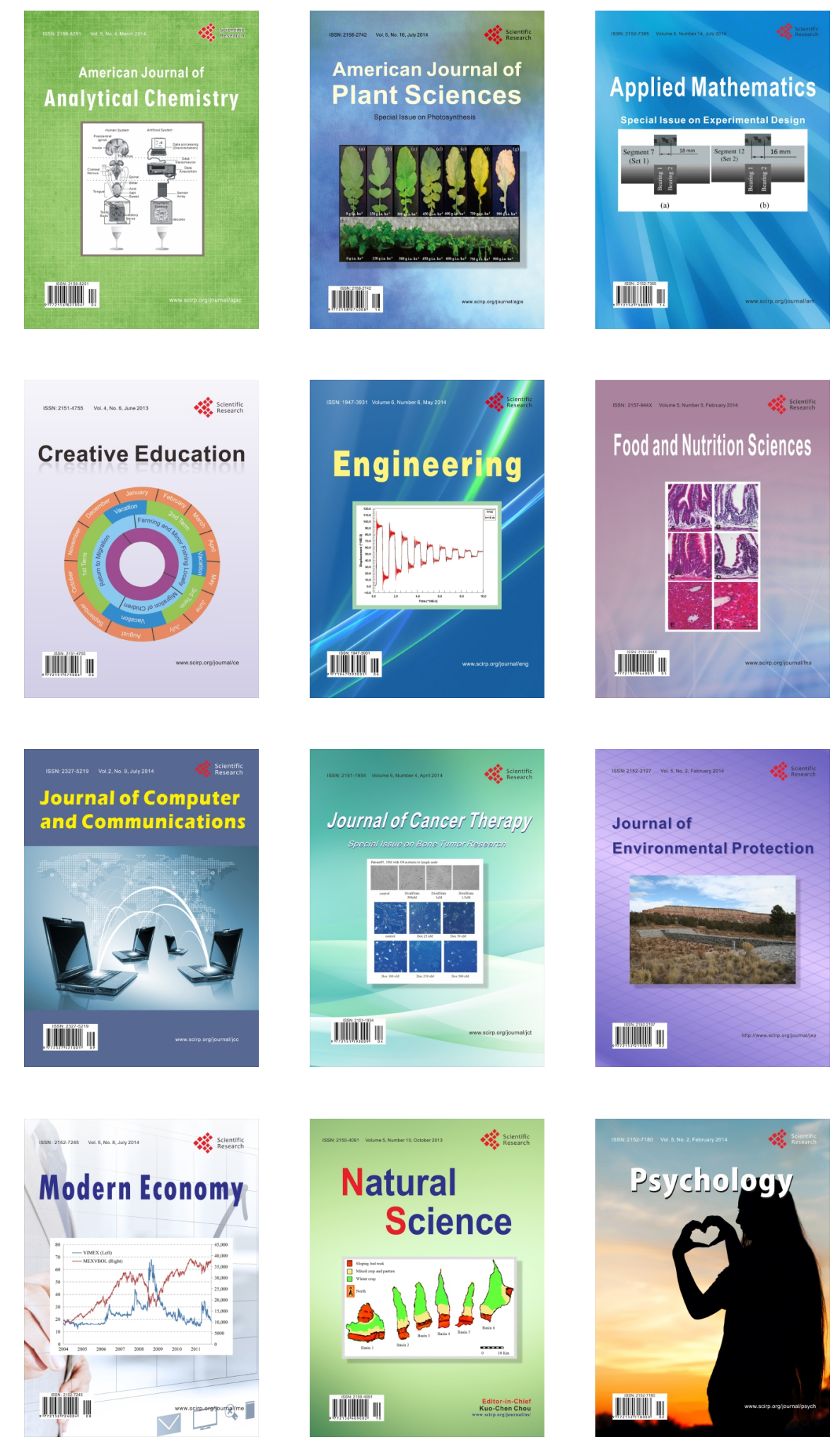